\title{
VÝVOJ PRIAMYCH ZAHRANIL,NÝCH INVESTÍCIÍ VO VYBRANÝCH REGIÓNOCH
}

\section{DEVELOPMENT OF FOREIGN DIRECT INVESTMENTS IN SELECTED COUNTRIES}

\author{
Ing. Elena ĠRÁ, PHD. \\ Ing. Mariana DUBRA VSKÁ, PhD. \\ Katedra ekopnómie a ekonomiky $\mid$ Department of Economy and Economics \\ Fakulta manaǵmentu Faculty of Management \\ Preg்ovská univerzita v Preg்ve University of Preg்v in Preg் $v$ \\ $\bowtie$ Konġantínova 16, 08001 Preg̉ov, Slovak Republic \\ E-mail:elena.sira@unipo.sk,mariana.dubravska@unipo.sk
}

\begin{abstract}
Anotace
Llánok sa zaoberá analýzou tokov priamych zahraniḷných investícií vo yybraných krajinách. Pre analýzu boli zvolené nasledovné krajiny: L eská republika, MaN̦arsko, Po@̆ko a Slovensko. V! lánku popisujeme pozitíva plynúce z PZI pre krajiny. Následne analyzujeme vo vybraných krajinách mieru nezamestnanosti a úroveŔ minimálnej mzdy, keṆǵe ide o ukazovatele, ktoré sú dôleǵité pre investorov pri výbere cieQ̆vých krajín. V N̦alğj ! lasti analyzujeme výğku PZI vo vybraných krajinách vobdobí 2008 ï 2012. V závere uvádzame zhrnutia z vývoja PZI v uvedených regiónoch.
\end{abstract}

\section{Klíl ová slova}

priame zahraniḷ né investície, miera nezamestnanosti, minimálna mzda

\section{Annotation}

This article deals with the development of foreign direct investments. We analyse FDI in selected countries. We choose Czech Republic, Hungary, Poland and Slovakia for comparison. We describe positives for countries to export FDI. Then we analyse mentioned countries through unemployment rate and minimum wages, because these indicators are important for investors by choosing the target countries. Than we analyse the amount of FDI in selected countries in the period of 2008 ï 2012. Last, we make conclusions about the amount of FDI flows in mentioned regions.

Key words

foreign direct investment, unemployment rate. minimum wage.

JEL classification: R11

\section{Úvod}

Priame zahranil né investície podporujú rozvoj ekonomík, zvyğjú zamestnanosŠ v regiónoch a pozitívne vplývajú aj na obchodnú bilanciu. Zahraniḷ ní investori vstupujú na nové trhy z dôvodu diverzifikácie predaja, kvôli kvalifikovanej a lacnej pracovnej sile, li uǵ z dôvodu zvýǵenia obratu, alebo príleğitostí nových trhov. Podmienkou pre vstup je vğk atraktívne prostredie, ktoré sa spája s kvalitnou infrağruktúrou, s kvalifikovanou ale zároveR lacnou pracovnou silou a s mnoǵstvom potenciálnych zákazníkov. 


\section{Ciele a metodika}

CieQ̆m príspevku je analyzovaŠvývoj PZI vo vybraných krajinách a následne poukázaŠna rozdiely, príp. podobnosti v danej oblasti v uvedených krajinách.

Pre analýzu sme si vybrali obdobie rokov 2008 ï 2012. Hodnoty PZI a iných vybraných ukazovateŏv sme analyzovali v týchto krajinách:

- Leská republika,

- MaNarsko,

- PoQ̆́ko,

- Slovenská republika.

Najskôr sme v uvedených krajinách zhodnotili mieru nezamestnanosti a úroveŔ minimálnych miest, keṆǵe aj na tieto ukazovatele sa zameriava pozornosŠ budúcich investorov PZI. Následne sme hodnotili absolútne úrovne tokov PZI cez prílev a odliv PZI. Následne, pre lepg̈u komparáciu zvolených krajín sme pouǵili prepoḷ et tokov PZI ku HDP, aby mali závery z hodnotenia skúmaných krajín vyğgiu výpovednú hodnotu.

Údaje pre analýzu krajín v oblasti PZI a iných vybraných ukazovateQ̆v sme ḷ erpali zo ġatistík zverejnených Eurostatom, OECD a organizáciou UNCTAD. Teoretické podklady ku skúmanej problematike sme ! erpali z vedeckých ! lánkov uverejnených vo svetových cital ných databázach.

\section{Výsledky}

\section{Priame zahranil né investície - PZI}

V úvode tejto !̣asti sa pokúsime zadefinovaŠ termíny ako medzinárodný pohyb kapitálu a priame zahranil né investície.

Prvotný podnet pre medzinárodný pohyb kapitálu vyplýva z miery zhodnotenia kapitálu $\mathrm{v}$ jednotlivých krajinách. ÄKapitál sa presúva z domácej krajiny do krajiny s lepğmi moǵnosŠami zhodnotenia. Vyğgeje zhodnotenie kapitálu sa prejavuje v závislosti na forme investovaného kapitálu vo vyğgom zisku, vyğg்ch dividendách, vyğǵch úrokoch a pod.ñ (Kuneġová a kol., 2006). Medzinárodný pohyb kapitálu predstavuje presun ur!̣ itej hodnoty z jedného gaátu do druhého za tým úl elom, aby v nej pôsobila ako kapitál (Hel ková, Chapl áková, 2012).

PodQ̆ Kuneg̉ovej a kol. (2006) kapitál je moǵné do zahraniḷ ia investovaŠ v rôznych formách. Z hădiska typu investovaného kapitálu rozlig̉jjeme:

- Priame zahranil né investície,

- Portfóliové investície,

- Zahranil né vklady a úvery. (Kuneg̉ová a kol., 2006)

Z ḷasového hădiska je moğné !̣leniŠ kapitál na krátkodobý (kratğe ako 1 rok) a na dlhodobý (investovanie na viac ako 1 rok).

Z hădiska vlastníctva môǵeme kapitál ! leniŠna tieto skupiny:

- Súkromný kapitál (investorom je súkromný subjekt),

- Gátny kapitál (investorom je ǵát),

- Medzinárodný kapitál (investorom je medzinárodný subjekt). (Kuneġvá a kol., 2006)

Významnú formu medzinárodného pohybu kapitálu tvoria priame zahraniḷ né investície (PZI). V súl asnej ekonomickej teórii neexistuje jednotná definícia priamych zahranil ných investící́. PodQ̊ OECD ÄPriama zahranil ná investícia odráǵa zámer rezidenta jednej ekonomiky (priamy investor) získaŠtrvalú úl asŠv subjekte, ktorý je rezidentom v inejekonomike ako ekonomika investora (priama investícia).ñ (OECD, 2008, s. 45). PodQ̆ NBS (2008) ÁPriame zahranil né investície odráǵajú trvalý záujem rezidentského subjektu jednej krajiny (priamy investor) v rezidentskom subjekte inej krajiny (podnik s priamymi zahranil nými investíciami). Zahน̌Rajú vğetky transakcie uskutol Ŕované medzi 
priamym investorom a podnikom s priamymi zahranil ným investíciami.ñ $\mathrm{V}$ uvedených definíciách je jasne vidieŠ dôraz na prekral ovanie regionálnych hraníc pri tokoch PZI. V týchto definíciách je prvotnou charakteristikou PZI ich transregionálne pôsobenie.

PodQ̆ Kuneǵovej a kol. (2006) PZI predstavujú Ănákup majetku v jednej krajine investorom druhej krajiny, ktorý im umoǵní kontrolu podniku a rozhodovanie o Rom.ñ Dudág்(2006) definuje PZI ako Ănákup zahranil ných aktív na úl ely kontroly. Pod kontrolou rozumieme kontrolu hospodárenia firmy, ktorej aktíva sa nakúpili ờDudág 2006, s. 5). Teda definície Kuneǵovej a Dudáğ sa zhodujú v tom, ǵe PZI slúǵia investorom aj na kontrolovanie hospodárenia firiem v zahranil í, kde majú investované svoje aktíva.

Pri vývoze PZI chcú investori zarábaŠna g̣pecifických podmienkach národnej ekonomiky. ĂPZI spolu so správne nastaveným politickým pozadím môǵu krajine poskytnúŠ finan! nú stabilitu, podporiš hospodársky rozvoj a zvýğ Š blahobyt spolol nosti.ñ (Kuzmiğn ï Ġg̉ová, 2013) Investor napr. získa prístup $\mathrm{k}$ lacnej pracovnej sile. Významným stimulom sú tieǵ úspory, dane, clá. Vg̉etky tieto skutol nosti sa v konel nom dôsledku premietnu na výğke zisku. Celkový ekonomický prínos, ktorý je definovaný v zisku je v pomere s investil ným rizikom (napr. Šaǵkosti s transfermi zisku do materskej krajiny alebo riziko dvojitého zdanenia). VzŠah rizika a celkového moǵného prínosu potom usmerŔuje medzinárodný pohyb kapitálu. PZI neprináǵajú výhody len investorom, ale taktieǵ hostiteQ̆kej krajine. (Kuneg̉oá a kol., 2006)

HostiteQ̆ká krajina spravidla od PZI oḷ akáva zvýġenie zamestnanosti, produkcie, prístup na nové trhy, transfer nových technológií a celkové oğivenie regiónu. (Kuneǵová a kol., 2006). ĂPZI sú prostriedkom zabezpel ujúcim transfer technológii, zvyğijú zamestnanosŠ a tieǵ prispievajú $\mathrm{k}$

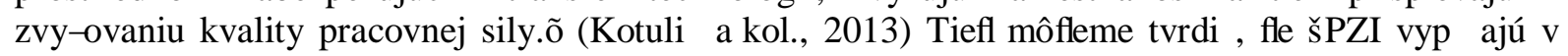
hostiteQ̆kej krajine medzeru medzi investíciami a domácimi úsporami.ñ

If $=($ S-I $)+(T-G) \quad($ Smataník, 2008)

\section{Vývoj PZI vo vybraných regiónoch}

V úvode prináġme vybrané ukazovatele hodnotených krajín. Krajiny vyváǵajúce PZI sa pri výbere cieØ̆vých krajín riadia aj aktuálnou ponukou pracovných síl, úrovŔou nezamestnanosti, t.j, li je pracovná sila k dispozícii a tieǵaj výǵkou minimálnej mzdy, ktorá je potrebná na kalkuláciu nákladov na prácu.

Tab. 1: Nezamestnanos Šv \%

\begin{tabular}{|l|r|r|r|r|r|}
\hline & \multicolumn{1}{|c|}{2008} & \multicolumn{1}{|c|}{2009} & \multicolumn{1}{c|}{2010} & \multicolumn{1}{c|}{2011} & \multicolumn{1}{c|}{2012} \\
\hline L̦eská republika & 4,4 & 6,8 & 7,4 & 6,8 & 7,0 \\
\hline MaŇarsko & 7,9 & 10,1 & 11,2 & 11,0 & 11,0 \\
\hline PoQ̆ko & 7,2 & 8,3 & 9,7 & 9,8 & 10,2 \\
\hline Slovensko & 9,5 & 12,1 & 14,4 & 13,7 & 14,0 \\
\hline
\end{tabular}

Zdroj: vlastné spracovanie na základe údajov Eurostatu

V tab. 1 je uvedená nezamestnanosŠ v analyzovaných krajinách v období 2008 ï 2012. Vǵtky skúmané krajiny dosahujú pomerne vysokú mieru nezamestnanosti. Najvyğg̉a miera nezamestnanosti bola v celom období na Slovensku, naopak, najniǵğa bola v L̦eskej republike.

Tab. 2: Minimálna mzda v EUR

\begin{tabular}{|l|c|c|c|c|c|}
\hline & \multicolumn{1}{|c|}{2008} & 2009 & \multicolumn{1}{c|}{2010} & 2011 & \multicolumn{1}{c|}{2012} \\
\hline Ĺeská republika & 334,83 & 309,10 & 311,39 & 328,61 & 312,01 \\
\hline MaN̦arsko & 293,08 & 263,30 & 256,99 & 293,11 & 323,17 \\
\hline PoQ̆ko & 335,99 & 286,61 & 317,58 & 347,34 & 353,04 \\
\hline Slovensko & 268,17 & 295,50 & 307,70 & 317,00 & 327,00 \\
\hline
\end{tabular}

Zdroj: vlastné spracovanie na základe údajov Eurostatu 
Lo sa týka vývoja minimálnej mzdy podă tab. 2, vidíme, ǵe v roku 2012 bola minimálna mzda vo vg̈etkých analyzovaných krajinách na pribliǵne rovnakej úrovni. KeṆǵe ide o susediace krajiny, tak $\mathrm{v}$ tomto ukazovateli nie sú markantné rozdiely medzi analyzovanými regiónmi. Ak by bola v niektorej z uvedených krajín výrazne rozlị ná úroveŔ minimálnej mzdy od ostatných krajín, bol by z okolitých krajín výrazný presun pracovných síl práve do tejto krajiny.

V nasledujúcej ! asti sa budeme venovaŠ analýze PZI vo vybraných krajinách. V tab. 3 ako aj v nasledujúcom grafe je znázornený vývoj prílevu PZI do nami analyzovaných krajín. Najväl ğ objem prílevu PZI bol v PoQ̣ku. Tam v prvých g̣yroch analyzovaných rokoch objem PZI rástol, no v roku 2012 sa jeho výğky výrazne znígilla oproti predchádzajúcim rokom.

Vývoj v oblasti prílevu PZI v L̦eskej republike je pomerne vyrovnaný. Hoci v rokoch 2009 a 2011 bo zaznamenaný prepad výǵky PZI oproti predchádzajúcim rokom, aj napriek tejto skutol nosti je to krajina s druhým najväl ğ́m prílevom PZI za celé sledované obdobie po PoQ̆ku. ĂJednou zo silných stránok Ḷeskej republiky je relatívne lacná a kvalifikovaná pracovná sila.ñ (Wokoun ï Krejl ová, 2013)

Najmenğ prílev PZI bol zaznamenaný v Slovenskej republike. V rokoch 2009-2012 jeho objem síce rástol, no dosahované hodnoty boli výrazne pod hodnotami ostatných analyzovaných krajín. ĂAvğak hospodárska Slovenska sa prikláŔa k aktívnej podpore investorov prostredníctvom investil ných stimulov.ñ (Kotuli! a kol., 2013) Slovensko je aj napriek nepriaznivej situácii v nízkom objeme PZI aj naN̦alej atraktívne pre investorov, pretoǵe má nízke konkuren! né náklady na pracovnú silu a pracovná sila je aj dostatoḷ ne vzdelaná (ako vyplýva aj z Tab. 1 a 2.). ÁSlovensko predstavuje relatívne malú a otvorenú ekonomiku, ktorá spolu so súl asnou sektorovou ġruktúrou predstavuje vo veăkej miere závislosŠna PZI.ñ (Kuzmig̈n ï Ġg̉ková, 2013)

Tab. 3: Prílev PZI v mil. EUR

\begin{tabular}{|l|c|c|c|c|r|}
\hline & 2008 & 2009 & 2010 & 2011 & \multicolumn{1}{c|}{2012} \\
\hline L̦eská republika & 4665,512 & 2116,739 & 4441,009 & 1676,107 & 7660,726 \\
\hline MaŇarsko & 4574,704 & 1442,545 & 1564,181 & 4163,693 & 9741,06 \\
\hline PoQ̆ko & 10731,69 & 9352,797 & 10035,13 & 13676,51 & 2426,925 \\
\hline Slovensko & 3520,665 & $-4,39655$ & 1279,931 & 1549,788 & 2043,772 \\
\hline
\end{tabular}

Zdroj: vlastné spracovanie na základe údajov UNCTAD

\section{Graf 1: Prílev PZI}

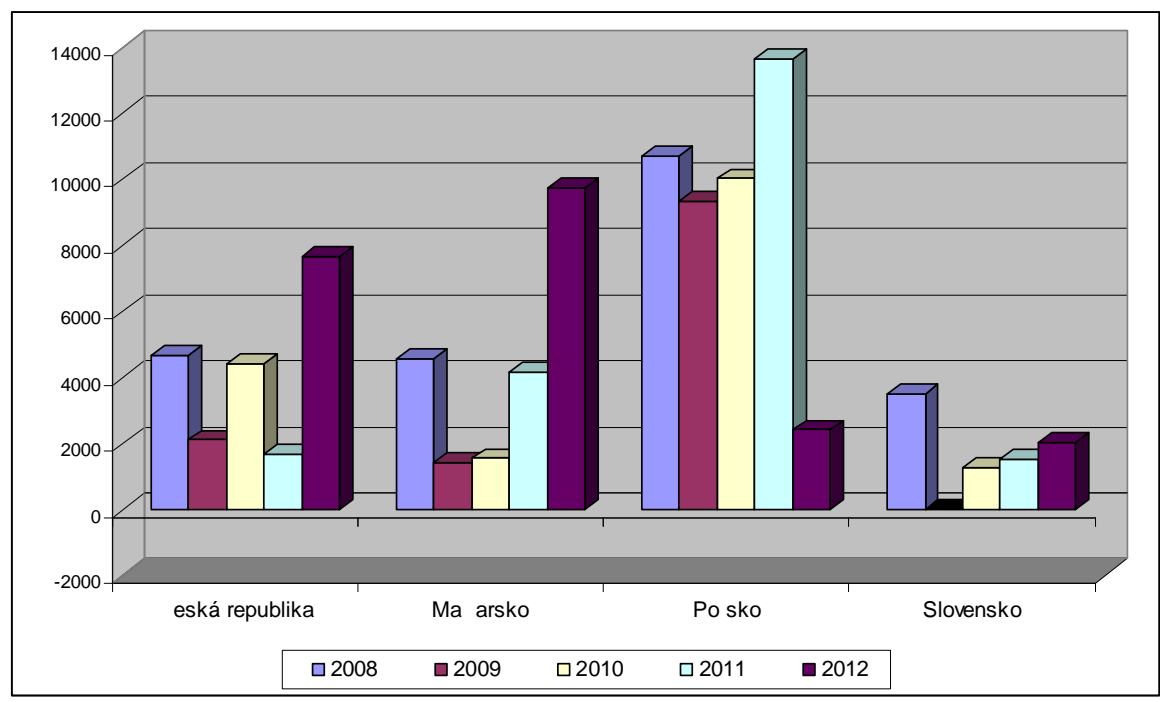

Zdroj: vlastné spracovanie na základe údajov UNCTAD 
Pod odlivom PZI rozumieme investície slovenských, ! eských, poQ̆kých a maN̦arských rezidentov v zahranil í. Tab. 4 a následne aj graf 2 nám uvádzajú hodnoty odlivu PZI v analyzovaných krajinách. V priemere za celé sledované obdobie bol v PoQ̆ku zaznamenaný najväl ğ odliv PZI. AK skúmame jednotlivé roky, tak výrazne najvyğǵ odliv bol v roku 2012 dosahovaný v MaṆarsku. Najniğğe hodnoty odlivu PZI dosahuje v celom sledovanom období Slovenská republika.

Tab. 4: Odliv PZI v mil. EUR

\begin{tabular}{|l|c|r|r|r|r|}
\hline & \multicolumn{1}{|c|}{2008} & \multicolumn{1}{c|}{2009} & \multicolumn{1}{c|}{2010} & \multicolumn{1}{c|}{2011} & \multicolumn{1}{c|}{2012} \\
\hline L̦eská republika & 3126,565 & 686,6806 & 843,8672 & $-236,782$ & 969,6559 \\
\hline MaN̦arsko & 1615,733 & 1361,595 & 820,7738 & 3394,396 & 7650,53 \\
\hline Po@̆ko & 3192,489 & 3398,53 & 5226,353 & 5215,376 & $-646,484$ \\
\hline Slovensko & 397,8506 & 654,0876 & 684,2591 & 354,4767 & $-53,1191$ \\
\hline
\end{tabular}

Zdroj: vlastné spracovanie na základe údajov UNCTAD

Graf 2: Odliv PZI

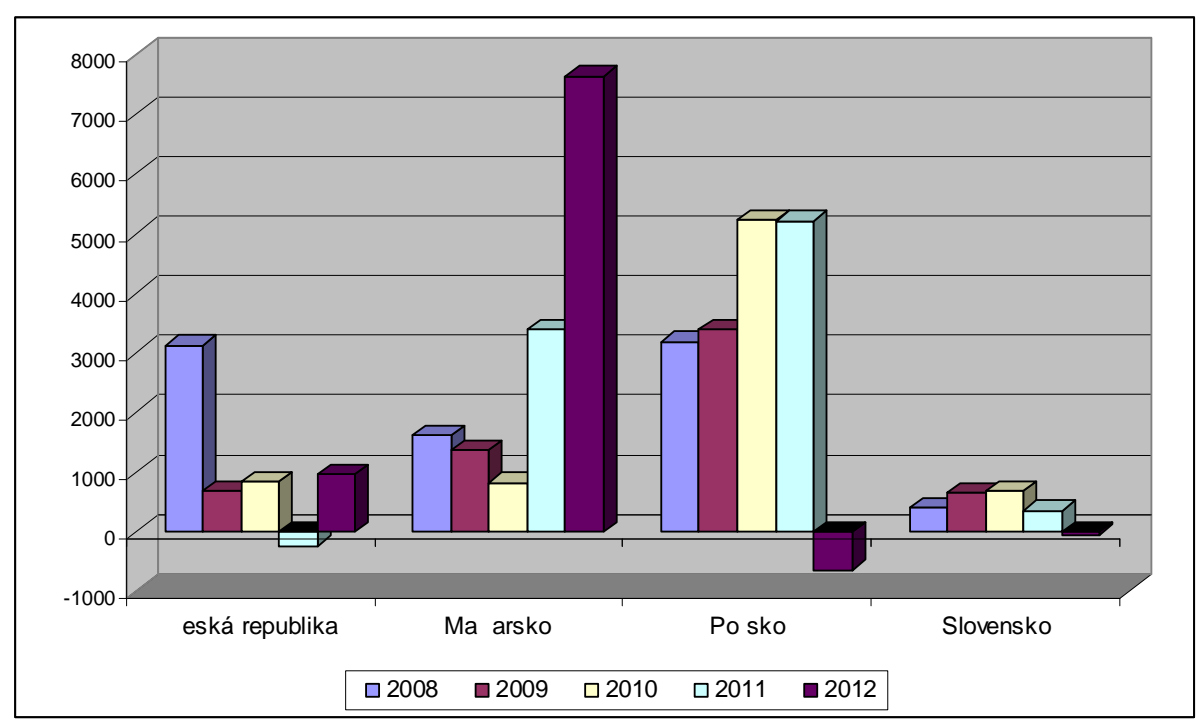

Zdroj: vlastné spracovanie na základe údajov UNCTAD

Uvedené hodnoty prílevu a odlivu PZI uvádzané za jednotlivé skúmané krajiny sú relatívne, keṆgge tieto hodnoty neodzrkadQ̆ijú stav daných ekonomík, ale uvádzajú len absolútne hodnoty. Preto v N̦alğch tabuQ̆ách prináğame údaje o príleve a odlive PZI ku HDP. Takto majú údaje PZI výrazne vyğg̉u vypovedaciu hodnotu. $\mathrm{V}$ tab. 5 sme najskôr uviedli hodnoty HDP $\mathrm{v}$ beǵných cenách $\mathrm{v}$ mil. EUR pre analyzované krajiny.

\section{Tab. 5: HDP v mil. EUR}

\begin{tabular}{|l|r|c|c|c|r|}
\hline & \multicolumn{1}{|c|}{2008} & \multicolumn{1}{c|}{2009} & \multicolumn{1}{c|}{2010} & \multicolumn{1}{c|}{2011} & \multicolumn{1}{c|}{2012} \\
\hline L̦eská republika & \multicolumn{1}{c|}{163033,4} & 142610,2 & 143882,9 & 156994,9 & 142074,4 \\
\hline MaŇarsko & 111535,6 & 91595,67 & 92539,49 & 100311,2 & 90113,9 \\
\hline PoQ̆ko & 382891 & 311645,2 & 339769,3 & 371819,5 & 354281,3 \\
\hline Slovensko & 68176,68 & 63089,21 & 63093,34 & 69479,85 & 66406,37 \\
\hline
\end{tabular}

Zdroj: vlastné spracovanie na základe údajov OECD

V tab. 6 uvádzame hodnoty prílevu PZI ku HDP. Výrazne najvyg̣gie hodnoty boli dosahované v roku 2012 v MaṆarsku, kde prílev PZI ku HDP bol viac ako 10 \%-ný. Ak extrahujeme od výkyvov vo vývoji, tak môǵeme tvrdiŠ ǵe v analyzovaných krajinách boli dosahované hodnoty prílevu PZI na HDP na úrovni cca 2- $3 \%$. 
Tab. 6: Prílev PZI ku HDP v \%

\begin{tabular}{|l|r|r|r|r|r|}
\hline & \multicolumn{1}{|c|}{2008} & \multicolumn{1}{c|}{2009} & \multicolumn{1}{c|}{2010} & \multicolumn{1}{c|}{2011} & \multicolumn{1}{c|}{2012} \\
\hline Leská republika & 2,86 & 1,48 & 3,09 & 1,07 & 5,39 \\
\hline MaN̦arsko & 4,10 & 1,57 & 1,69 & 4,15 & 10,81 \\
\hline PoQ̆ko & 2,80 & 3,00 & 2,95 & 3,68 & 0,69 \\
\hline Slovensko & 5,16 & $-0,01$ & 2,03 & 2,23 & 3,08 \\
\hline \multicolumn{7}{|c}{ Zdroj: vlastné vópol ty na základe údajov OECD a UNCTAD }
\end{tabular}

Výrazne niğğe hodnoty boli dosahované pri odlive PZI ku HDP. Výrazne najvyğga hodnota odlivu PZI ku HDP bola dosiahnutá v roku $2012 \mathrm{v}$ MaṆarsku na úrovni skoro 8,5\%. Najniǵg̉e hodnoty tohto ukazovateă boli v celom sledovanom období dosahované v Ḷeskej republike. Ak extrahujeme od výkyvov vo vývoji, tak môǵeme tvrdiŠ, ǵe v analyzovaných krajinách boli dosahované hodnoty odlivu PZI ku HDP na úrovni cca 1 ï 1,5\%, l, o sú hodnoty pribliǵne o polovicu niǵğe ako boli dosahované pri príleve PZI ku HDP.

Tab. 7: Odliv PZI ku HDP v \%

\begin{tabular}{|l|r|r|r|r|r|}
\hline & \multicolumn{1}{|c|}{2008} & \multicolumn{1}{c|}{2009} & \multicolumn{1}{c|}{2010} & \multicolumn{1}{c|}{2011} & \multicolumn{1}{c|}{2012} \\
\hline L̦eská republika & 1,92 & 0,48 & 0,59 & $-0,15$ & 0,68 \\
\hline MaN̦arsko & 1,45 & 1,49 & 0,89 & 3,38 & 8,49 \\
\hline PoQ̊ko & 0,83 & 1,09 & 1,54 & 1,40 & $-0,18$ \\
\hline Slovensko & 0,58 & 1,04 & 1,08 & 0,51 & $-0,08$ \\
\hline \multicolumn{7}{|c|}{ Zdroj: vlastné vópol ty na základe údajov OECD a UNCTAD }
\end{tabular}

\section{Záver}

Analyzované krajiny sú svojou ekonomickou úrovŔou a geografickou polohou zaujímavé pre investorov. Pri porovnávaní úrovní ekonomík cez vybrané ukazovatele, a tieǵaj pri porovnávaní tokov PZI sme dospeli k záveru, ǵe analyzované krajiny dosahujú porovnateĞé hodnoty, ak sa údaje interpretujú cez súhrnné ukazovatele. Pri absolútnom vyjadrení je vidieŠ mnohé výrazné odliğnosti a nerovnováhu, ktoré vğłk pri relatívnom prepoḷte zmiznú a údaje sú pre analyzované krajiny porovnateĞé bez výrazných výkyvov a rozdielností.

\section{Literatúra}

[1] DUDÁĠ T., (2006). Priame zahranil né investície vo svetovom hospodárstve. Bratislava: Ekonóm. ISBN 80-225-2139-6. p. 160.

[2] Eurostat statistics, (2008) [online]. [cit. 2014-3-23]. Dostupné z: <http://epp.eurostat.ec.europa.eu/portal/page/portal/employment_unemployment_lfs/data/main_tables>

[3] HEL KOVÁ, J., CHAPḶÁKOVÁ, A., (2012). Súl asnosŠ perspektívy svetovej ekonomiky. Kog̉ce: EQUILIBRIA. ISBN 978-80-8143-005-3

[4] KOTULIL, R. a kol., (2013). Stock of foreign direct investment and its impact on the sustainable development of the regions in the Slovak Republic. In 16th International Colloquium on Regional Sciences. Conference Proceedings. Brno: Masarykova univerzita. pp. 162-167. ISBN 978-80-210-6257-3. DOI 10.5817/CZ.MUNI.P210-6257-2013-7.

[5] KUNEǴOVÁ, H. a kol., (2006). Sv Пová ekonomika nové jevy a perspektivy. Praha : C. H. Beck. ISBN 807179-455-4. p.319.

[6] KUZMIǴN, P., ĠĠOVÁ, A., (2013). The quality oe entrepreneurial environment as a factor of foreign direct investments inflows. In Quality innovation prosperity / Kvalita inovácia prosperita XVII/2 ï 2013. ISSN 1338-984X.

[7] OECD Benchmark Definition of Foreign Direct Investment, 4th Edition, (2008). [online]. [cit. 2014-4-8]. Dostupné z: <http://www.oecd.org/daf/inv/mne/statistics.htm>.

[8] Priame zahraniḷné investície. NBS, (2008). [online]. [cit. 2014-4-8]. Dostupné z: <ttp://www.nbs.sk/_img/Documents/STATIST/SPB/PZI/PZI_2008.pdf>. 
[9] SMATANÍK, P., (2008). Priame zahranil né investície na Slovensku (so zameraním na Continental Matador Rubber, s.r.o.) [online]. [cit. 2014-4-1]. Dostupné z: <www.vse.cz/vskp/show_file.php?soubor_id=20419>.

[10] UNCTAD, (2014) [online]. [cit.

$<$ http://unctadstat.unctad.org/TableViewer/tableView.aspx>

[11] WOKOUN, R., KREJL,OVÁ, N., (2013). Socio-economic level and regional competitiveness factors of regions in the Czech Republic. In 16th International Colloquium on Regional Sciences. Conference Proceedings. Brno: Masarykova univerzita. pp. 30-41. ISBN 978-80-210-6257-3. DOI 10.5817/CZ.MUNI.P210-6257-2013-3.

Tento príspevok je výstupom z projektu KEGA-032PU-4/2013. 